\title{
Multi-component gas emission measurements of the active lava lake of Nyiragongo, DR Congo
}

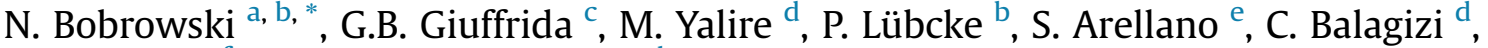 \\ S. Calabrese ${ }^{\mathrm{f}}$, B. Galle ${ }^{\mathrm{e}}$, D. Tedesco ${ }^{\mathrm{g}, \mathrm{h}}$ \\ a Institut für Geowissenschaften, Johannes Gutenberg Universität, Mainz, Germany \\ ${ }^{\mathrm{b}}$ Institut für Umweltphysik, Ruprecht-Karls Universität, Heidelberg, Germany \\ ${ }^{\mathrm{c}}$ Institute Nazionale Geofisica e Vulcanologia, Palermo, Italy \\ d Observatoire Volcanologique de Goma, Goma, Democratic Republic of Congo \\ e Department of Earth and Space Sciences, Chalmers University of Technology, Göteborg, Sweden \\ ${ }^{\mathrm{f}}$ Dipartimento Scienze della Terra e del Mare, University of Palermo, Palermo, Italy \\ ${ }^{g}$ Department of Environmental Sciences, Second University of Napoli, Caserta, Italy \\ ${ }^{\mathrm{h}}$ Istituto Nazionale di Geofisica e Vulcanologia, Roma, Italy
}

\section{A R T I C L E I N F O}

\section{Article history:}

Received 13 September 2015

Received in revised form 21 May 2016

Accepted 19 July 2016

Available online xxx

\section{Keywords:}

Nyiragongo

Gas composition variations

Lava lake level changes

\begin{abstract}
A B S T R A C T
Between 2007 and 2011 four measurement campaigns (June 2007, July 2010, June 2011, and December 2011) were carried out at the crater rim of Nyiragongo volcano, DR Congo. Nyiragongo is one of the most active volcanoes in Africa. The ground-based remote sensing technique Multi-Axis Differential Optical Absorption Spectroscopy (MAX-DOAS), which uses scattered sunlight, the in-situ Multi-Component Gas Analyzer System (Multi-GAS) and alkaline impregnated filter were simultaneously applied during all field trips. The bromine monoxide to sulfur dioxide $\left(\mathrm{BrO} / \mathrm{SO}_{2}\right)$ and carbon dioxide to sulfur dioxide $\left(\mathrm{CO}_{2} /\right.$ $\mathrm{SO}_{2}$ ) molar ratios were determined, among other ratios. During the different field trips variations of the level of the lava lake up to several tens of meters were observed during intervals of the order of minutes up to days and also between the years. The measured gas ratios presented covariations with the lava lake level changes. $\mathrm{BrO} / \mathrm{SO}_{2}$ ratios and $\mathrm{CO}_{2} / \mathrm{SO}_{2}$ ratios showed similar behavior. Annual $\mathrm{CO}_{2} / \mathrm{SO}_{2}$ and $\mathrm{BrO} / \mathrm{SO}_{2}$ average values are generally positively correlated. In June 2011 increased $\mathrm{BrO} / \mathrm{SO}_{2}$ as well as increased $\mathrm{CO}_{2} / \mathrm{SO}_{2}$ ratios have been observed before a sudden decrease of the lava lake.

Overall the $\mathrm{Cl} / \mathrm{S}$ ratio, determined by filter-pack sampling, shows an increasing trend with time, which is accompanied by a decreasing sulfur dioxide flux, the later measured nearly continuously by automated MAX-DOAS instruments since 2004.

Mean gas emission fluxes of $\mathrm{CO}_{2}, \mathrm{Cl}$ and 'minimum-BrO' fluxes are calculated using their ratio to $\mathrm{SO}_{2}$. The first two show an increase with time, in contrast to the $\mathrm{SO}_{2}$ fluxes.

A simple conceptual model is proposed which can explain in particular the June 2011 data, but as well our entire data set. The proposed model takes up the idea of convective magma cells inside the conduit and the possible temporary interruption of part of the cycling. We propose than two alternatives to explain the observed gas emission variation: 1 . It is assumed that the diffuse and fumarolic degassing could have significant influence on measured gas composition. The measured gas composition might rather represent a gas mixture of plume, diffuse and fumarolic degassing than only representing the volcanic plume. 2. It is proposed that the interruption of the convection has taken place in the upper part of the conduit and deep degassing of $\mathrm{CO}_{2}$ and bromine initially continues while mixing already with gas emissions from an ageing source, which is characterized by an already diminishing sulfur content. These complex process but as well as the gas mixing of different sources, could explain general features of our dataset, but can unfortunately neither be confirmed nor disproven by the data available today.
\end{abstract}

(๑) 2016 Elsevier Ltd. All rights reserved.

\footnotetext{
* Corresponding author. Institut für Geowissenschaften, Johannes Gutenberg Universität, Mainz, Germany.

E-mail address: nbobrows@uni-mainz.de (N. Bobrowski).
} 


\section{Introduction}

Nyiragongo $\left(1^{\circ} 31^{\prime} 20^{\prime \prime} \mathrm{S}, 29^{\circ} 15^{\prime} 0^{\prime \prime} \mathrm{E}\right)$ is one of eight volcanoes in the Virunga volcanic chain, in the East African Rift System (Fig. 1). It has a height of about $3470 \mathrm{~m}$ and it is famous among volcanologists for its large ( $46,550 \mathrm{~m}^{2}$, Burgi et al., 2014) semi-permanent lava lake. Nyiragongo is an exceptional volcano regarding some of its properties. In fact, it has the lowest lava viscosity recorded worldwide (e.g. Hertongen et al., 1985; Platz et al., 2004; Chakrabarti et al., 2009), which is even lower than the frequently effusively erupting volcano Nyamuragira, located $\sim 13 \mathrm{~km}$ westward. Nyiragongo is characterized by a relatively unusual magmatic composition, comprising highly alkaline and silica under saturated basaltic rocks (Platz et al., 2004; Chakrabarti et al., 2009).

Nyiragongo gives an extraordinary possibility to directly observe magma movements because the volcano feeds a semipermanent lava lake since more than eight decades with only short interruptions for instance after the 1977 and 2002 eruptions. Movements of magma, partly visible at the lava lake surface, can thus be directly related to geochemical and/or geophysical observations. This was recognized by H. Tazieff (e.g. Tazieff, 1975) who organized the first scientific field campaigns inside the active crater of Nyiragongo at the end of the nineteen-fifties $(1958,1959)$. Unfortunately, due to its location as a political hot spot in the North Eastern part of the DR Congo close to the border to Rwanda (Fig. 1), it was and it is still not an ideal area to undertake extended broad research campaigns, although a few of them have taken place.

We carried out four measurement campaigns between 2007 and 2011 to study the chemical interactions of volcanic gases with the atmosphere at an open "boiling" lava surface. The atmospheric issues and plume chemistry were partly discussed already in Bobrowski et al., 2015. In this work, we will focus on the relationship between the changes detected within the gas composition of the volcanic plume and our visual observations of volcanic activity changes itself.

\section{Short volcanic history and earlier measurements}

After the first documented field survey of von Goetzen and Prignitz, who climbed the top of Nyiragongo in 1894 (Götzen, 1897), a lava lake seems apparent at least since 1928, when continuous gas emission and an often reddish-glowing sky were observed and reported (Tazieff, 1977; Pottier, 1978). H. Tazieff made the first documented discovery of the lava lake in 1948. The first scientific measurements were conducted also by $\mathrm{H}$. Tazieff during a field trip in 1958, when the lava lake level was relatively low, but still closer to the rim than today (Tazieff, 1977). Besides measurements of seismicity and radioactivity, rock and gas samples were taken, the latter analyzed by Chaigneau et al. (1960). Chaigenau and coauthors obtained the first gas composition for the major elements of Nyiragongo's plume, characterizing it as $\mathrm{CO}_{2}$-rich plume with nearly $48 \% \mathrm{CO}_{2}$ of total gas volume.

Due to the limited access to Nyiragongo for political reasons, as mentioned earlier, relatively few field investigations have been carried out since that period. Ground based gas sampling before this work (of hot fumaroles and plume) took place in 1958, 1959, 1972, 2005, 2006, and 2007 (Sawyer et al., 2008 and references therein). Under favorable weather conditions satellite images allowed further determination of the $\mathrm{SO}_{2}$ amounts since at least 2002, however, often without distinction between the plumes of Nyamuragira and Nyiragongo because of limitations in spatial resolution. Furthermore low temperature degassing and rain sampling has been carried out extensively during the last decade (e.g. Tedesco et al., 2010; Cuoco et al., 2013; Calabrese et al., 2014). Results of rain sampling and of low temperature degassing and their variations will not be used for comparison with our data set in the discussion related to volcanic activity changes in this paper. The reason is the added complexity of such data through the interaction of gases with water, ash and soil and therefore incompatibility for a direct comparison with the data taken during the presented field campaigns.

\section{Methods}

\subsection{DOAS measurements}

The miniaturized MAX-DOAS system, as described by Bobrowski et al., 2015 for the 2007 study, was also used during the field surveys in 2010 and 2011. The system consists of a temperaturestabilized, airtight aluminum box with a commercial miniature spectrometer (OceanOptics Inc., USB2000) inside, an entrance optics with a field of view approximately $0.6^{\circ}$ and a stepper motor mounted on one side of the metal box. The instrument is commonly set up on a tripod and the motor moves the whole metal box to point the entrance optics at different elevation angles between 0 and $180^{\circ}$. Data acquisition was performed by the special software package DOASIS (Kraus et al., 2001) running on a notebook computer. For more details see e.g. Bobrowski et al., 2007.

The collected spectra were evaluated with the software WinDoas V2.10 from IASB (Belgium Institute for Space Aeronomy; Fayt and van Roozendael, 2001) to derive the slant column densities (SCD) of $\mathrm{BrO}$ and $\mathrm{SO}_{2}$ from the recorded spectra. Because scattered sunlight has been used as light source, the solar Fraunhofer lines had to be removed carefully in order to allow sensitive measurements of trace species. A background spectrum was used as Fraunhofer reference spectrum (FRS), which was taken only shortly after the acquisition of spectra inside the plume and care was taken to guarantee that the FRS contained as little absorption by the volcanic plume as possible (Bobrowski et al., 2015).

The presented $\mathrm{BrO}$ results were evaluated in the wavelength region from 332 to $352 \mathrm{~nm}$ including $4 \mathrm{BrO}$ absorption bands. A polynomial of 2 nd order was chosen to remove broadband structures. Reference spectra of $\mathrm{BrO}, \mathrm{NO}_{2}, \mathrm{O}_{3}, \mathrm{SO}_{2}, \mathrm{O}_{4}$, a 'Ring-spectrum' (Bussemer, 1996), and the FRS were simultaneously fitted to the measurement spectra using a nonlinear least squares method (Platt and Stutz, 2008), which is implemented in the evaluation software WinDoas.

$\mathrm{SO}_{2}$ was analyzed between 362 and $390 \mathrm{~nm}$ as described in Bobrowski et al. (2010). Besides $\mathrm{SO}_{2}$, two $\mathrm{O}_{3}$ references for 223 and $246 \mathrm{~K}$, one $\mathrm{O}_{4}$ reference and one $\mathrm{NO}_{2}$ reference at $246 \mathrm{~K}$ were included in the DOAS fit. Also a Ring spectrum and the same Fraunhofer reference spectrum as for the BrO fit (spectra taken outside the plume) were taken into account. A 3rd order polynomial was applied to remove broad band structures and a shift and 1st order squeeze were allowed for the measured spectra.

Furthermore, automated scanning DOAS systems (NOVAC-instruments - see Galle et al., 2010), which have been installed at Rusayo, Sake and Kingi on the southwest flank of Nyiragongo about 8-20 km from the summit (Fig. 1) in March 2004 and afterwards, were used to investigate the long-term evolution of Nyiragongo's $\mathrm{SO}_{2}$ emissions and the $\mathrm{BrO} / \mathrm{SO}_{2}$ ratios whenever above the detection limits. The telescope of the scanning DOAS instrument is attached to a scanning device consisting of a mirror attached to a computer-controlled stepper-motor providing a mean to scan the field-of view of the instrument over $180^{\circ}$ (Galle et al., 2010). Here the scanner was mounted at the end of a hollow iron bar and fixed to the exterior of a hut for all three stations. The optical fiber and cables connecting the scanning device were fed through the iron bar to the spectrometer inside the hut. The systems are powered by solar panels, and data is transferred in real time to the Goma 


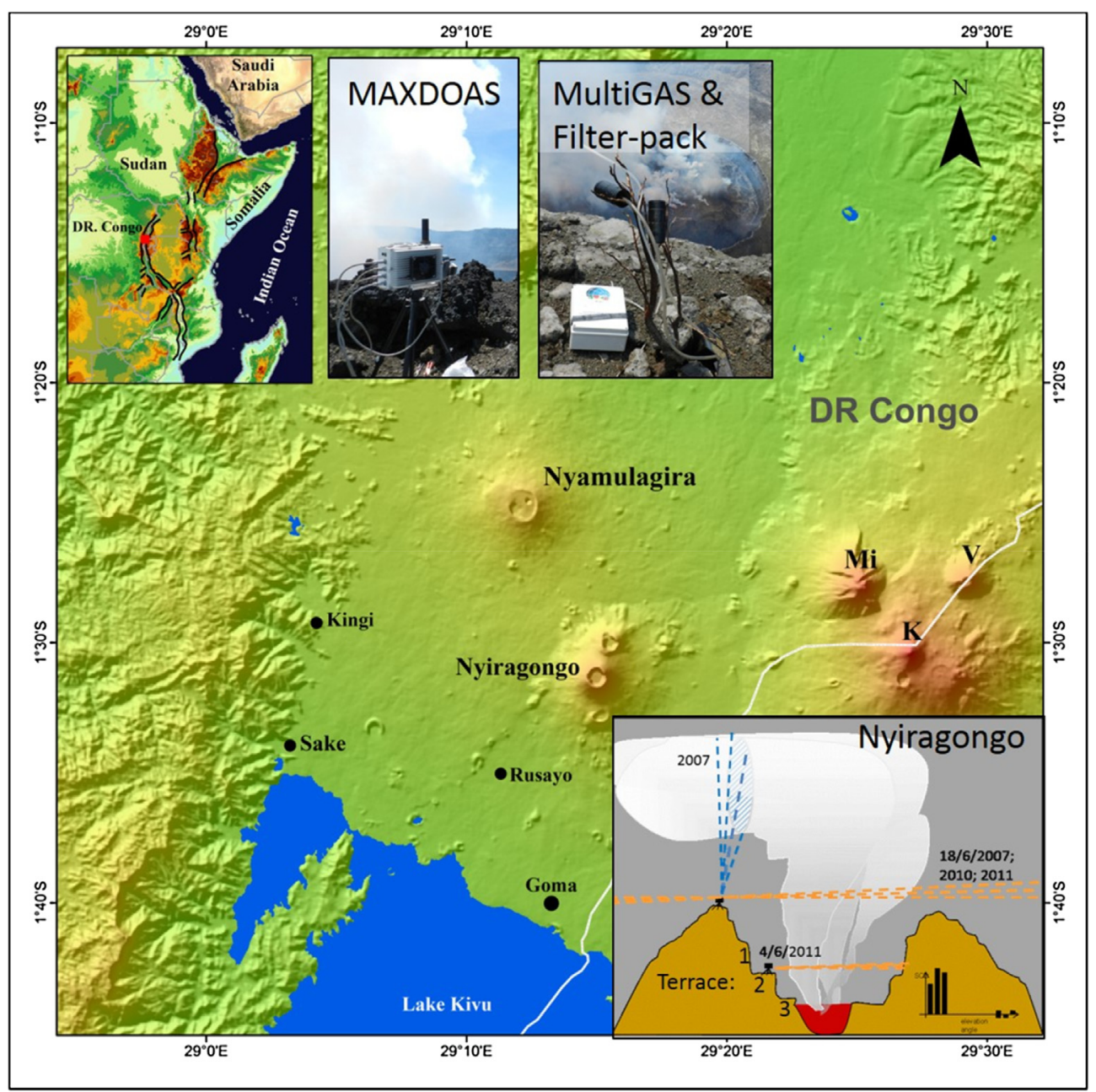

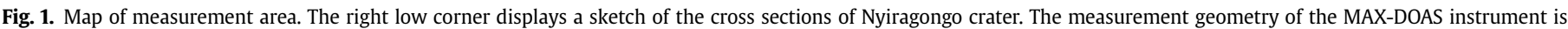

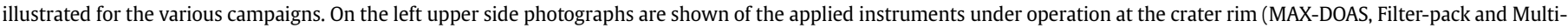
GAS for a description see section: Methods.).

Volcanological Observatory (GVO), using a 57,400 baud radio mo$\mathrm{dem}$. The average of 15 spectra are acquired at variable exposure times depending on the amount of available radiation, but limited to $2 \mathrm{~s}$, on each scan position, with $7.2^{\circ}$ angular resolution, providing a full emission measurement every $\sim 5 \mathrm{~min}$. For more details of the instrument see Galle et al., 2010 and Arellano et al., (this issue). Unfortunately, there are several months of data interruption over the years due to instrumental failures. Nevertheless overall changes on longer time scales can be investigated.

The $\mathrm{BrO} / \mathrm{SO}_{2}$ ratio was determined from measurements of two NOVAC stations at Nyiragongo (Rusayo and Sake) downwind following the procedure outlined in Lübcke et al., 2014. Spectra were co-added from four consecutive scans (due to fewer available spectra before October 2007 only 5 spectra were co-added, afterwards 10 spectra per scan for reference and plume spectra were coadded) and evaluated for $\mathrm{BrO}$ and $\mathrm{SO}_{2}$. Daily averages were calculated for all spectra with an $\mathrm{SO}_{2}$ content above $7 \times 10^{17}\left[\mathrm{~mole} / \mathrm{cm}^{2}\right]$. Fig. 6 shows daily averages of the $\mathrm{BrO} / \mathrm{SO}_{2}$ ratio for days with more than five individual $\mathrm{BrO} / \mathrm{SO}_{2}$ ratios. From this data monthly mean ratios were calculated and are shown in Fig. 6 as black crosses.

\subsection{Multi-GAS and filter-pack measurements}

A Multi-Component Gas Analyzer System (Multi-GAS) and active alkaline trap sampling (filter packs) (see Aiuppa et al., 2006 and Aiuppa et al., 2005; respectively for details) were simultaneously operated to determine the mixing ratios of the major volcanic species in the plume of Nyiragongo. The Multi-GAS uses an electrochemical sensor for $\mathrm{SO}_{2}$ and a Non-Dispersive Infra-Red (NDIR) spectrometer (e.g. Aiuppa et al., 2006; Shinohara, 2005), allowing real-time detection of $\mathrm{SO}_{2}$ and $\mathrm{CO}_{2}$ concentrations in the plume with a $2 \mathrm{~s}$ sampling time. From this data a $\mathrm{CO}_{2} / \mathrm{SO}_{2}$ molar ratio was determined for each measurement day. Plume air was also pumped at a constant flow rate of about $4-5 \mathrm{l} / \mathrm{min}$ through filter-packs, which consisted of 3 in-series $(1 \mathrm{M}) \mathrm{NaHCO}_{3}$-treated cellulose filters contained in a polycarbonate holder. The concentrations of the acidic gases $\left(\mathrm{SO}_{2}\right.$ and $\left.\mathrm{HCl}\right)$ were later determined from the amounts of $\mathrm{S}$ and $\mathrm{Cl}$ adsorbed on the filters. Filters were eluted with Millipore water and the obtained solutions were oxidized with $\mathrm{H}_{2} \mathrm{O}_{2}$ and analyzed by ion chromatography (IC).

According to Wittmer et al. (2014) when the last filter of the pack contained non negligible amounts $(>10 \%)$ of the total trapped species, results should be discarded. This limit was set to ensure that the filter were not saturated of trapped species of interest.

Both methods encountered difficulties due to the highly diluted plume at the crater rim of Nyiragongo. This resulted in higher uncertainties than normally obtained for the Multi-GAS and in particular for the filter-pack measurements. We therefore included 
only relatively short time sequences of the normally 60 min lasting Multi-GAS data collection on each measurement day, the time was chosen regarding the highest $\mathrm{SO}_{2}$ concentrations. The filter-pack resulted in very low concentrations and we included data, which had up to $20 \%$ of total gas concentration on the last filter as indicated in Table 1 . In other words, one can generally assume that the total amount of the gas of interest was still completely trapped, however not meeting anymore the guidelines of a perfect sample. Further, unfortunately, the original data files for the single filters from 2007 are not anymore available to us and therefore we cannot exclude saturation for the data of this field season. Only the higher abundant species, chlorine and sulfur, are considered and we discuss only their average value per campaign. Given errors are the variability during one field campaign.

\section{Measurements and results}

In June 2007, July 2010, June and December 2011 spectroscopic, electro-chemical sensor and filter-pack measurements of the volcanic plume of Nyiragongo volcano were carried out from its crater rim as well as inside the crater in one occasion (4th June 2011) (see Fig. 1 for locations, measurement geometry and instrumental setups and Table 1 as well as Figs. 3-5 for results).

The ground-based remote sensing technique MAX-DOAS, applied at the edge of the crater rim of the volcano, was used to determine the $\mathrm{BrO} / \mathrm{SO}_{2}$ ratio as described above. In addition, often simultaneously to the MAX-DOAS measurements, or at least within a time difference of a few hours, filter-pack and in-situ spectroscopic $\mathrm{CO}_{2}$ and electrochemical $\mathrm{SO}_{2}$ measurements were conducted at the crater rim.

On a longer, more continuous time scale the $\mathrm{BrO} / \mathrm{SO}_{2}$ ratio was determined from measurements of two NOVAC stations at Nyiragongo (Rusayo and Sake) downwind following the procedure outlined in Lübcke et al., 2014, see also above.

Nyiragongo plume has been recently characterized with high bromine content, but relatively low chlorine abundances (Bobrowski et al., 2015). Also Sawyer et al. (2008) had determined low chlorine content from FTIR measurements - that showed $\mathrm{Cl} / \mathrm{S}$ ratios of $0.053-0.056$. The data from our first measurement campaign in June 2007 confirmed the low chlorine content in the plume of Nyiragongo. But since 2010 the $\mathrm{Cl} / \mathrm{S}$ ratio has significantly increased as discussed later. The $\mathrm{CO}_{2} / \mathrm{SO}_{2}$ ratios obtained in our study vary widely between 1.3 and 11.5 . However, they are lower when compared to measurements performed in the earlier and late eighties, which showed $\mathrm{CO}_{2} / \mathrm{SO}_{2}$ ratios of up to 20 (Le Guern, 1987; Gerlach, 1980).

In the following, data and observations from each single fieldsurvey are described in more detail, and afterwards we discuss the entire dataset.

\subsection{Results from 2007}

The $\mathrm{BrO} / \mathrm{SO}_{2}$ ratio was measured during four days within a oneweek stay at the crater rim of Nyiragongo in the second half of June 2007. The level of the lava lake was changing slightly (in the order of several meter) during the week of observation. During the first days of investigation the lava lake level was significantly below the third terrace (see Fig. 1 for geometry and photo from 18th June 2007 in Fig. 2a). For better comparison measurements on the 18th of June will not be considered in the comparison to other measurements taken in 2007, but will be used for the comparison with data of the following years. The reason is that we used the same measurement geometry on 18th June 2007 and during all measurements in 2010 and 2011. In contrast on 19th, 20th and 24th June 2007 the entrance optic was not pointed directly above the crater as it was done on 18th June 2007, in 2010 and 2011 (see Fig. 1) for that reason an older plume had been measured on those days.

$\mathrm{A} \mathrm{BrO} / \mathrm{SO}_{2}$ ratio of about $12.5 \times 10^{-6}$ was determined on 19 th of June while decreasing on June 20th, 2007, to about $6.8 \times 10^{-6}$ and even lower on June 24 th, 2007 with a value of ca. only $4.6 \times 10^{-6}$. In the early morning hours of the next day an overflow of the lava lake was observed occurring on the third terrace (see Fig. 1 and photo of Fig. 2b). Data taken on the 18th of June with the same geometry as in 2010 and 2011 resulted in a $\mathrm{BrO} / \mathrm{SO}_{2}$ ratio of $2.3 \times 10^{-6}$. The $\mathrm{CO}_{2} /$ $\mathrm{SO}_{2}$ ratios varied between 5 and 10 with the minimum determined on the 22nd June and the maximum on 18th June. The mean $\mathrm{Cl} / \mathrm{S}$ ratio was determined to 0.08 in 2007 (see also Bobrowski et al., 2015).

\subsection{Results from 2010}

Unfortunately gas measurements could be carried out only during the first half of the week because of otherwise bad weather conditions.

The lava lake level was about $100 \mathrm{~m}$ higher than in 2007 (about $385 \mathrm{~m}$ below the rim). The third terrace was heightened and a small cone had formed around the crater-lake on this terrace. Generally, the $\mathrm{SO}_{2}$ gas emission flux had been halved from 2007 to 2010 (see Arellano et al., this issue). Although no direct comparison between the emission of June 2007 and July 2010 could be made, because the NOVAC stations were not functional during June 2007.

In 2010 , the $\mathrm{BrO} / \mathrm{SO}_{2}$ ratio was determined in a distance of about $385 \mathrm{~m}$ above the lava lake, therefore the plume investigated might have been only slightly younger as the one on the 18th June 2007, assuming a similar rising speed of the plume inside the crater. The

Table 1

Mean $\mathrm{BrO} / \mathrm{SO}_{2}, \mathrm{CO}_{2} / \mathrm{SO}_{2}, \mathrm{Cl} / \mathrm{S}$ ratios for each measurement day and all campaigns are presented - standard deviations for the regressions lines of the $\mathrm{BrO}-\mathrm{SO}_{2}$ and $\mathrm{CO}_{2}-\mathrm{SO}_{2}$ correlation plots are given as well as $\mathrm{R}^{2}$ of all ratios.

\begin{tabular}{|c|c|c|c|c|c|}
\hline Date & $\mathrm{BrO} / \mathrm{SO}_{2} 10^{-6}$ & $\mathrm{R}^{2}$ & $\mathrm{CO}_{2} / \mathrm{SO}_{2}$ & $\mathrm{R}^{2}$ & Information \\
\hline $18 / 6 / 2007$ & $2.3 \pm 0.6$ & 0.89 & - & & $0.12^{\mathrm{a}}$ \\
\hline $19 / 6 / 2007$ & $12.5 \pm 0.6$ & 0.90 & - & & $0.06^{\mathrm{a}}$ \\
\hline $20 / 6 / 2007$ & $6.8 \pm 1.5$ & 0.65 & 5.7 & & $0.06^{\mathrm{a}}$ \\
\hline $21 / 6 / 2007$ & - & & 5.7 & & $0.09^{\mathrm{a}}$ \\
\hline $22 / 6 / 2007$ & - & & 5 & & $0.08^{a}$ \\
\hline $23 / 6 / 2007$ & - & & 8 & & $0.06^{a}$ \\
\hline $24 / 6 / 2007$ & $4.6 \pm 0.6$ & 0.65 & 9 & & $0.11^{\mathrm{a}}$ \\
\hline $18 / 7 / 2010$ & $1.7 \pm 1.0$ & 0.37 & $4.7 \pm 0.22$ & 0.69 & \\
\hline $19 / 7 / 2010$ & $15 \pm 1.2$ & 0.86 & $2.1 \pm 0.10$ & 0.77 & \\
\hline $20 / 7 / 2010$ & $4.5 \pm$ & & $1.3 \pm 0.10$ & 0.74 & $\begin{array}{l}0.45 \text { (highly error } \\
\text { prone -last filter } \\
\text { still close to } 30 \% \text { of } \\
\text { total chlorine) }\end{array}$ \\
\hline $21 / 7 / 2010$ & $4.3 \pm 0.7$ & 0.80 & - & & \\
\hline $1 / 6 / 2011$ & $12.0 \pm 0.9$ & 0.83 & $9.7 \pm 6.3$ & 0.78 & - \\
\hline $2 / 6 / 2011$ & $11.3 \pm 0.9$ & 0.76 & $9.9 \pm 1.1$ & 0.86 & 0.14 \\
\hline $3 / 6 / 2011$ & $12.9 \pm 0.9$ & 0.90 & $11.5 \pm 3.7$ & 0.6 & - \\
\hline $4 / 6 / 2011$ & & & & & - \\
\hline $5 / 6 / 2011$ & $7.2 \pm 0.4$ & 0.93 & $8.7 \pm 1.4$ & 0.68 & 0.27 \\
\hline $6 / 6 / 2011$ & $4.7 \pm 0.4$ & 0.84 & $2.8 \pm 0.4$ & 0.81 & - \\
\hline $10 / 12 / 2011$ & $4.4 \pm 0.4$ & 0.87 & - & & 0.56 \\
\hline $11 / 12 / 2011$ & $7.2 \pm 0.6$ & 0.85 & - & & 0.15 \\
\hline $12 / 12 / 2011$ & $7.6 \pm 0.6$ & 0.82 & - & & 0.14 \\
\hline $13 / 12 / 2011$ & $5.2 \pm 0.6$ & 0.85 & - & & 0.27 \\
\hline $14 / 12 / 2011$ & $4.4 \pm 0.8$ & 0.75 & - & & 0.17 \\
\hline
\end{tabular}

2011 data were generally evaluated regarding Wittmer et al., 2014, however due to the very low concentrations the here presented data have an up to $20 \%$ fraction (instead of suggested 10\%) on filter c on the total budget (see Wittmer et al., 2014).

a Data were evaluated before Wittmer et al., 2014 and single filter values are not any more available - a review considering the guidelines is therefore not possible, unfortunately. 
$\mathrm{BrO} / \mathrm{SO}_{2}$ ratios determined in 2010 are generally a bit higher compared to the one determined on 18th June 2007, except for the one measured on 18th July 2010.

Another interesting observation was made on 20th July 2010. On this day the $\mathrm{BrO} / \mathrm{SO}_{2}$ ratio began to decrease during the measurements to a level where the BrO signal was below the detection limit. This occurred simultaneously to the overflow of the lava lake (see Fig. 3b for data and Photograph in Fig. 2). This effect is similar to what was observed in 2007, but on a much shorter time scale. The $\mathrm{CO}_{2} / \mathrm{SO}_{2}$ ratios varied between 1.3 and 4.7 during the campaign and hence are smaller than values obtained in 2007. The $\mathrm{Cl} / \mathrm{S}$ ratios showed a very high value of 0.45 . However, this value results only from one filter-sampling unit showing still nearly $30 \%$ of the total chlorine and sulfur amount on the last (third) filter (definitively higher than the recommended value for good quality data, which suggest less than $10 \%$ of the gas of interest on the last filter, Wittmer et al., 2014). No reliable alkaline trap data are available for the field campaign in 2010, mainly due to the unfavourable meteorological conditions (in particular high humidity) and generally low plume concentration at the crater rim.

\subsection{Results from 2011}

In June 2011 the meteorological conditions were exceptionally good for this environment (tropical climate zone), allowing measurements every single day of our stay at the crater rim. In comparison to July 2010 the level of the lava lake was generally a bit lower. It had been fallen far below the ridge of the cone on the 3rd terrace, which had remained at a similar height as the year before. No lava lake overflow could be observed on the third terrace during our stay. Instead, an impressive drop of about $25 \mathrm{~m}$ or more occurred in a matter of seconds or maximum minutes during the third night in the field on 3rd June 2011 (see also Burgi et al., 2014). This was in co-existence with a seismic swarm reported between Nyiragongo and Nyamuragira (OVG, personal communication). The "boiling activity" and convection was clearly enhanced of the lava lake surface superficial plates after this event (bigger waves, faster motions and enhanced degassing) for the following days and a further decreasing trend of the lava lake of about $2 \mathrm{~m} / \mathrm{d}$ was also observed (Burgi et al., 2014) during the rest of our stay. A similar MAX-DOAS measurement geometry as in 2010 was applied and the plume was measured at a distance of about $415-445 \mathrm{~m}$ from the lava lake surface (Burgi et al., 2014).

Both, $\mathrm{CO}_{2} / \mathrm{SO}_{2}$ and $\mathrm{BrO} / \mathrm{SO}_{2}$ ratios were significantly higher in comparison to the earlier measurements (measurements of 2007 and 2010) before the lava lake level dropped (see Table 1). Those ratios returned to more similar values as observed in July 2010 and December 2011 following the drop of the lava lake level, and accompanied by an enhanced activity of the lava lake.

In June 2011 the average $\mathrm{Cl} / \mathrm{S}$ ratios doubled in comparison to June 2007.

In December 2011 a second short field survey took place. The lava lake was at a higher level than when we had left it in June 2011, but still clearly below the rim of the cone, which had been first observed in 2010.

Unfortunately no $\mathrm{CO}_{2} / \mathrm{SO}_{2}$ data were obtained due to instrumental failures. The MAX-DOAS measurements were again taken at a distance of about $400 \mathrm{~m}$ above the lava lake. The $\mathrm{BrO} / \mathrm{SO}_{2}$ ratio was similar to the second half of the June 2011 measurements, slightly higher than in 2010. The same trend can be seen in the long-term data from the NOVAC-network (see Fig. 6). The $\mathrm{SO}_{2}$ gas emission flux of 2011 was significantly higher than the one determined in 2010
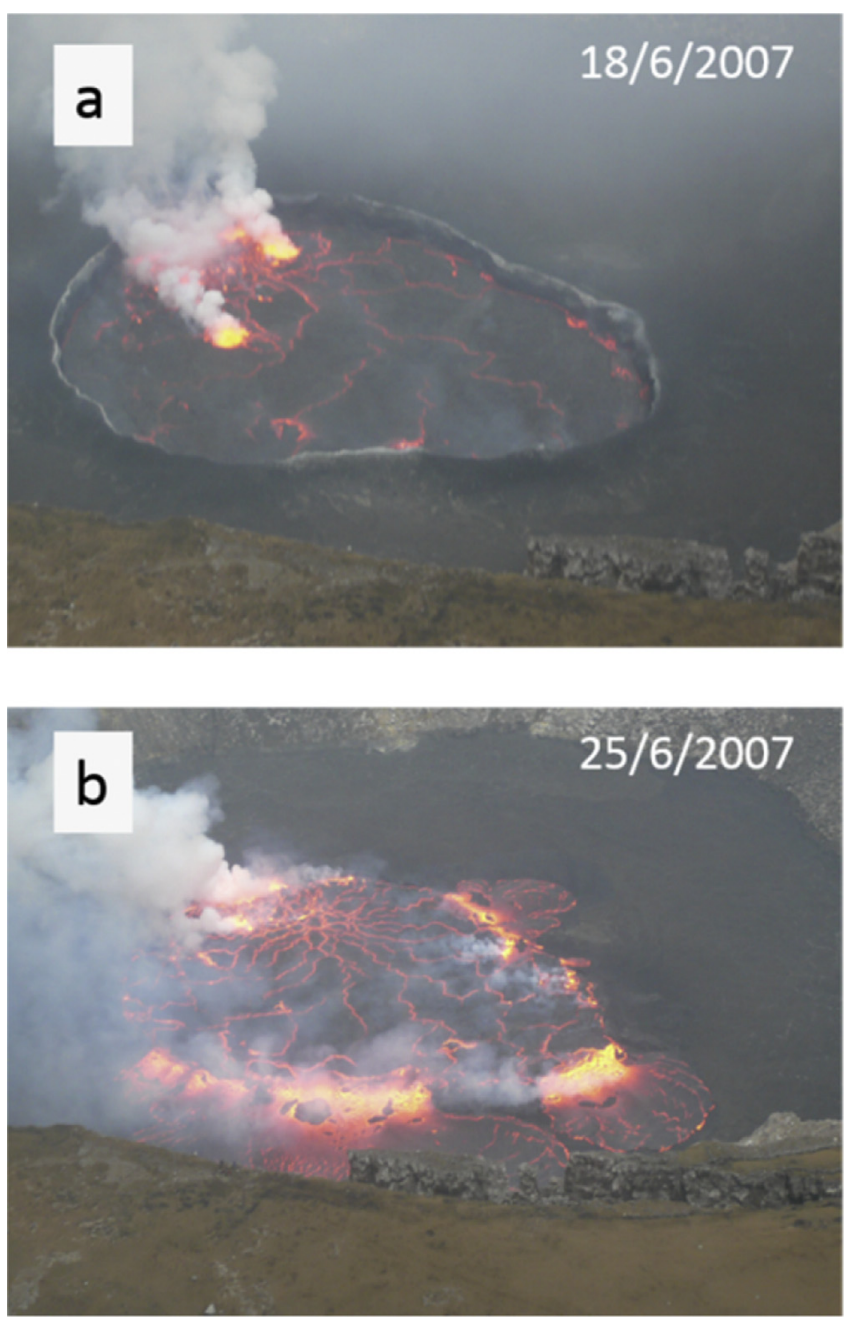

Fig. 2. (a) Photo of the lava lake taken in the beginning of the 2007 campaign, on 18 th June 2007. The lava lake level is noticeable below the level of the third terrace. (b) Photo of the lava lake taken on the last morning of the measurement campaign in 2007,25 th June 2007. The lava lake level increased significantly and an overflow of the lake is visible.

\subsection{Long-term $\mathrm{BrO} / \mathrm{SO}_{2}$ data of the NOVAC stations}

The $8-20 \mathrm{~km}$ downwind $\mathrm{BrO} / \mathrm{SO}_{2}$ ratio lies about an order of magnitude higher than the one observed at the crater rim. This is in agreement with other $\mathrm{BrO} / \mathrm{SO}_{2}$ measurements as well as model studies (see e.g. Platt and Bobrowski, 2015 for an overview on this argument). In the first years of observations (2004-2008) the ratio was determined to be at about $2-3 \times 10^{-5}$. Between the beginning of 2008 and the end of 2009 several gaps in the operation of the instruments occurred, which could not be solved promptly due to civil war, thus very few data were obtained during this time. After this lack of data the $\mathrm{BrO} / \mathrm{SO}_{2}$ values have been about doubled and show more scattering, which both are in agreement with the visual observation at the crater rim.

\section{Discussion}

The observed lava level changes, which were already recognized in the fifties (Tazieff, 1975) are still continuing on short (minutes to hours) and longer (weeks to years) timescales. To our knowledge, still no continuous or regular observation over the time of weeks, months or years could be successfully carried out and therefore the 


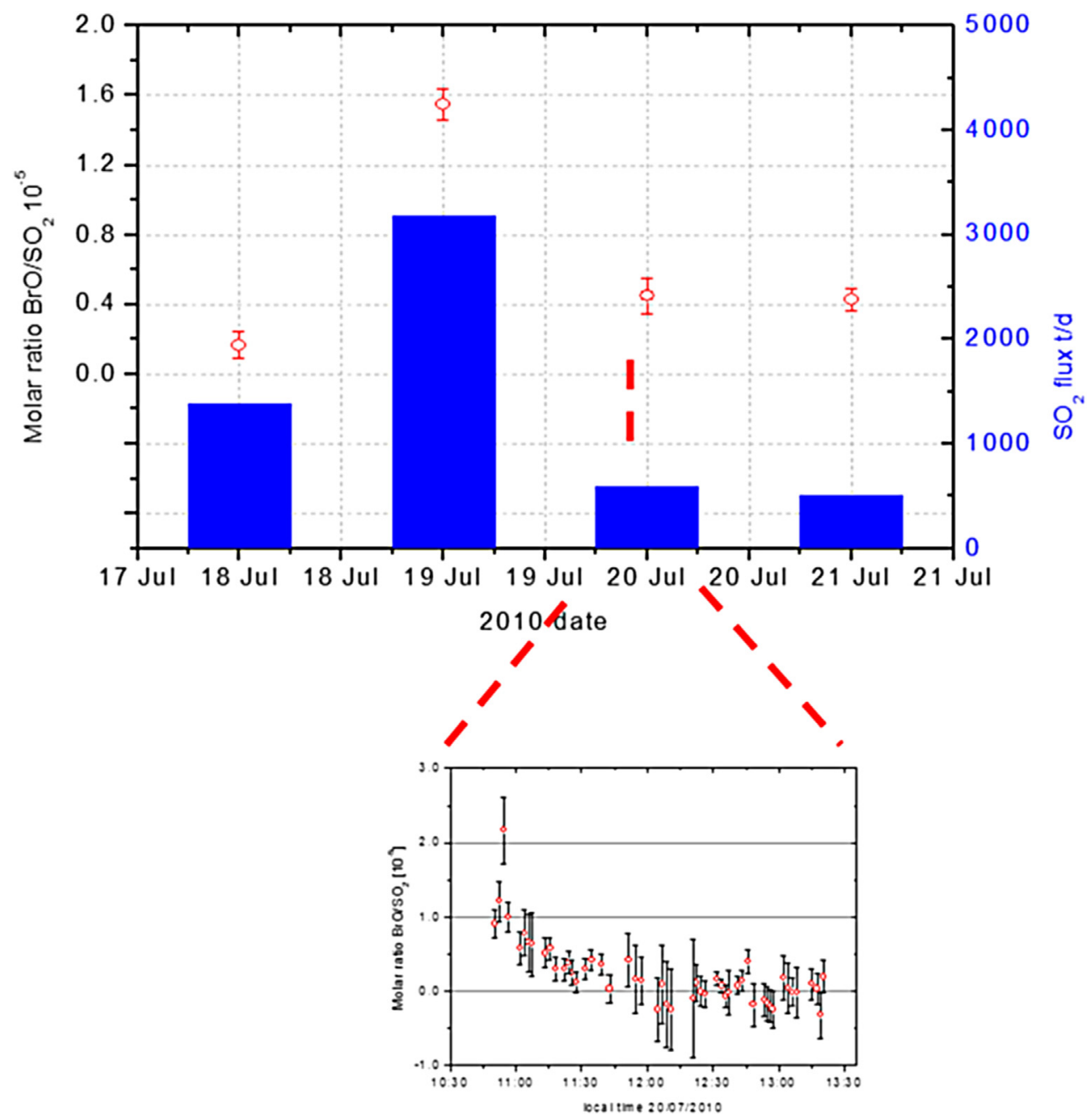

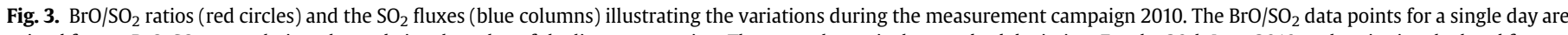

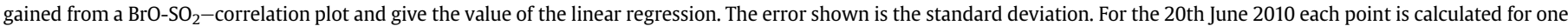

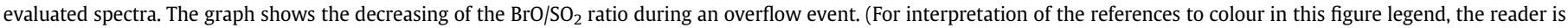
referred to the web version of this article.)

question of periodicities remains open, although an attempt has been undertaken installing webcams on the first terrace and results have been presented by Smets et al., 2016 as a conference contribution, recently. Unfortunately, the webcams did not resist for long time due to harsh meteorological conditions.

Although the lava lake was rising about $100 \mathrm{~m}$ from 2005 to 2007 - no significant changes in gas compositions were observed by Sawyer et al. (2008) during those years. At a first glance this is in contrast to our observations of gas ratio variations at the crater rim, but might be due to a stronger variability in the volcanic activity after 2007 (see Fig. 6). The larger variation (decrease) of the $\mathrm{SO}_{2}$ fluxes between 2007 and 2011 in comparison to more similar $\mathrm{SO}_{2}$ fluxes between 2005 and 2007 could serve as an argument for such an interpretation (see also Arellano et al., this issue). The $\mathrm{BrO} / \mathrm{SO}_{2}$ ratios also evaluated from the downwind installed NOVAC-stations show as well a higher variability after 2009 (see Fig. 6). The $\mathrm{BrO} / \mathrm{SO}_{2}$ time series presented in this work covers the years from 2004 until the beginning of 2012 . There are unfortunately several data gaps before 2009 - however the scattering of the monthly $\mathrm{BrO} / \mathrm{SO}_{2}$ averages is generally limited between 0 and $3.3 \times 10^{-5}$ during this time range. After 2009 larger monthly average $\mathrm{BrO} / \mathrm{SO}_{2}$ ratios are observed (between 2 and $7 \times 10^{-5}$ ). Comparing the single day data points the scattering enhances as well significantly after 2009.

During our four short-term observation periods described above, the lake level changed between our first visit in June 2007 and our last visit described in this article in December 2011, by a maximum difference of about $90 \mathrm{~m}$ from the determined minimum ( $476 \mathrm{~m}$ below crater rim) to the observed maximum ( $385 \mathrm{~m}$ below crater rim). Tens of meter changes were also observed during minutes to days of our observations. During the periods under investigations, the most significant short-term lake level change took place in the evening of 3rd June 2011, when the lava lake dropped about $25 \mathrm{~m}$ in a time of $<5 \mathrm{~min}$. Relatively high $\mathrm{BrO} / \mathrm{SO}_{2}$, high $\mathrm{CO}_{2} /$ $\mathrm{SO}_{2}$ ratios and low $\mathrm{SO}_{2}$ fluxes had preceded this dramatic change. Both ratios returned to values comparable to the ones determined in 2010 and December 2011 after the drop of the lava lake.

Generally, by comparing average campaign values of min. "BrO"fluxes and $\mathrm{CO}_{2}$ - fluxes a positive correlation is visible between these two (see also Fig. 5) over time. A positive correlation is also observed by comparing daily means of $\mathrm{BrO} / \mathrm{SO}_{2}$ and $\mathrm{CO}_{2} / \mathrm{SO}_{2}$ when data were collected under perfect meteorological conditions in June 2011 (see Fig. 4).

Further the 2011 data are characterized by higher $\mathrm{Cl} / \mathrm{S}$ in comparison to values determined in 2007 and also higher than the ones 
shown in Sawyer et al., 2008. The $\mathrm{BrO} / \mathrm{SO}_{2}$ ratios are difficult to compare for the measurements at the crater rim in 2007 and 2010 because only one data point in 2007 was collected with a similar plume age. The NOVAC data taken downwind provide a better possibility to compare the $\mathrm{BrO} / \mathrm{SO}_{2}$ ratios over a longer period of time. Fig. 6 shows that the $\mathrm{BrO} / \mathrm{SO}_{2}$ ratios varies over the considered time frame and shows higher $\mathrm{BrO} / \mathrm{SO}_{2}$ ratio in 2010 in comparison to the few data points available on 2007. Changes of the $\mathrm{BrO} / \mathrm{SO}_{2}$ ratios in context with volcanic activity variation have been reported at Mt Etna (Bobrowski and Giuffrida, 2012) and Nevado del Ruiz (Lübcke et al., 2014).

The June 2011 measurements show elevated $\mathrm{BrO} / \mathrm{SO}_{2}$ ratios during the first days in comparison to our earlier crater rim measurements of 2007 and 2010, followed by a decrease, which led to similar values as the ones determined in December of the same year. $\mathrm{CO}_{2} / \mathrm{SO}_{2}$ data follow the same trend as described for $\mathrm{BrO} / \mathrm{SO}_{2}$ in June 2011; unfortunately, no $\mathrm{CO}_{2} / \mathrm{SO}_{2}$ data are available for December 2011.

To our knowledge no other simultaneous $\mathrm{BrO} / \mathrm{SO}_{2}$ and $\mathrm{CO}_{2} / \mathrm{SO}_{2}$ ratios over periods of volcanic activity changes have been reported so far. $\mathrm{CO}_{2}$ get exsolved very early (under still relative high lithostatic pressure) from the magma. The fact that $\mathrm{CO}_{2} / \mathrm{SO}_{2}$ and $\mathrm{BrO} /$ $\mathrm{SO}_{2}$ ratios show a positive correlation can be seen as a further hind for a relatively low solubility of bromine in comparison to sulfur as already suggested in Bobrowski and Giuffrida (2012) and Lübcke et al. (2014).

The June 2011 data could be explained by assuming a partial interruption of the convective magma cycling in the conduit, as described by e.g. Sawyer et al., 2008. This would explain the decreasing of the total gas flux (see Fig. 4 as well as Sketch in Fig. 7a) and can also be confirmed by our visual observation of relatively slower movements on the lava lake surface. A possible assumption could be the build-up of a deeper laying foam layer, which might have 'disappeared' via cracks and partly through the lake surface on June 3, 2011 and the days afterwards causing the decrease of the lava lake level (see Fig. 7b). The enhanced $\mathrm{CO}_{2} / \mathrm{SO}_{2}$ ratios could be explained by a larger contribution of the fumarolic and diffuse soil degassing to the plume prior to the event, when the emitted amount of plume gas was decreasing (Fig. 7). We imagine the plume as a mixture of lake, fumarolic degassing and diffuse soil degassing, whereas the lake degassing presents usually the largest and most significant contribution. The fumarolic degassing inside Nyiragongo's crater shows very low sulfur content (Tedesco and Vaselli unpublished data). The question, which remains open in this conceptual model, is the enhanced $\mathrm{BrO} / \mathrm{SO}_{2}$ ratio prior 3rd June 2011.

Another possibility or an extension to the upper model which might explain the observed gas emission changes including the $\mathrm{BrO} / \mathrm{SO}_{2}$ enhancement is starting again with the assumption of an interruption of the convection inside the conduit. The dynamic of a lava lake can be quite complex. Cooling and crystallization produced by outgassing has to be counterbalanced by the influx of gasrich magma from below to maintain the lava lake for a sustained period of time. This influx can be periodic or also be characterized by irregular patterns (e.g. Witham et al., 2006; Witham and Llewellin, 2006).

An instability of the lava lake generated by a reduction of gas influx from depth could lead to a densification by degassing, cooling, and crystallization. We indeed observed quite reduced movements on the lava lake surface on the first days of June 2011. We now further would assume that the interruption of the magma convection takes place only in the upper part of the conduit.

$\mathrm{CO}_{2}$ and bromine, the later one we assume to exsolve also relatively early (relatively deep, as first suggested by Bobrowski and Giuffrida, 2012) would initially (1st June 2011) still continue to
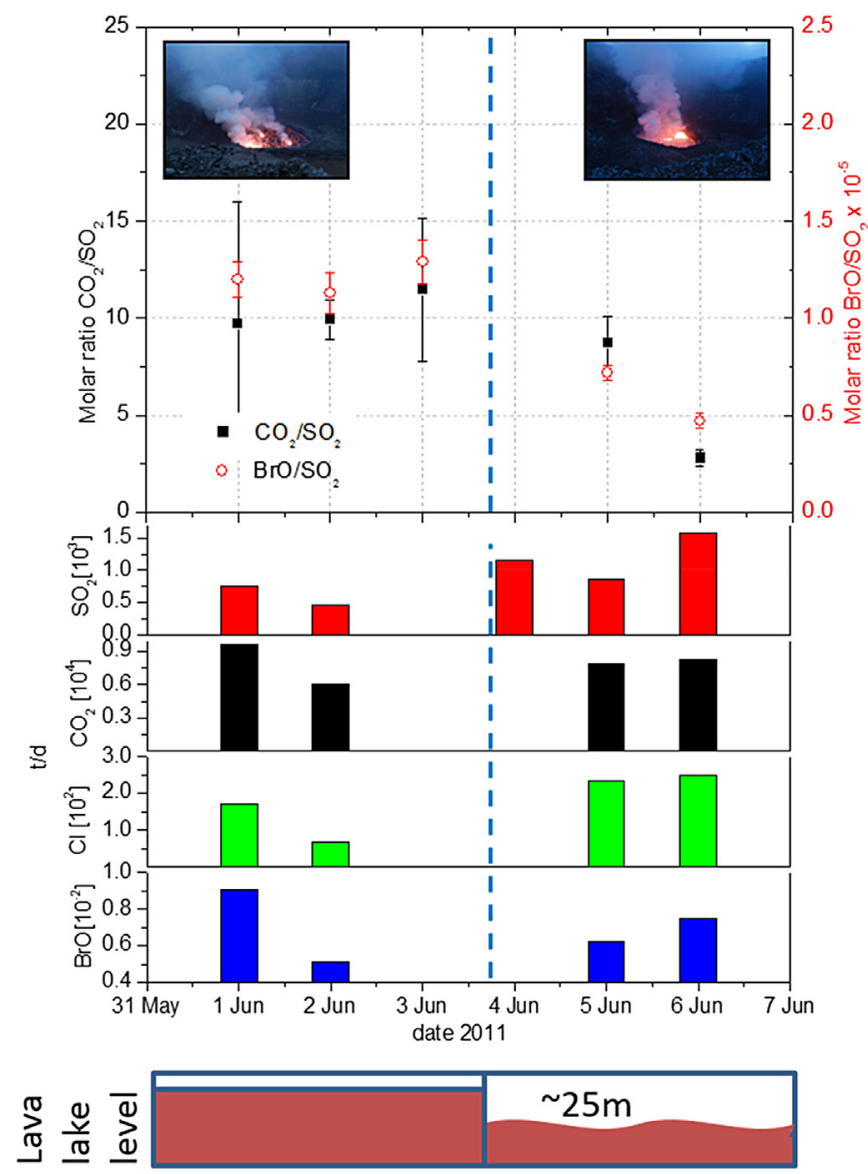

Fig. 4. $\mathrm{CO}_{2} / \mathrm{SO}_{2}$ (black rectangles) and $\mathrm{BrO} / \mathrm{SO}_{2}$ (red circles) ratios are shown as a function of date in the upper plot. Middle panel: fluxes of $\mathrm{SO}_{2}, \mathrm{Cl}, \mathrm{CO}_{2}, \mathrm{BrO}$ are presented as a function of date. The fluxes were calculated from the respective ratio to $\mathrm{SO}_{2}$. The $\mathrm{SO}_{2}$ flux was measured by the NOVAC instruments. Lava lake activity and level change are sketched in the lower panel. (For interpretation of the references to colour in this figure legend, the reader is referred to the web version of this article.)

degas as long as permeability has not decreased, significantly. $\mathrm{SO}_{2}$ and chlorine instead would show already typical features for an ageing lava body (1st June 2011), where $\mathrm{SO}_{2}$ starts to diminish and chlorine a bit later due to its late degassing mainly close to the

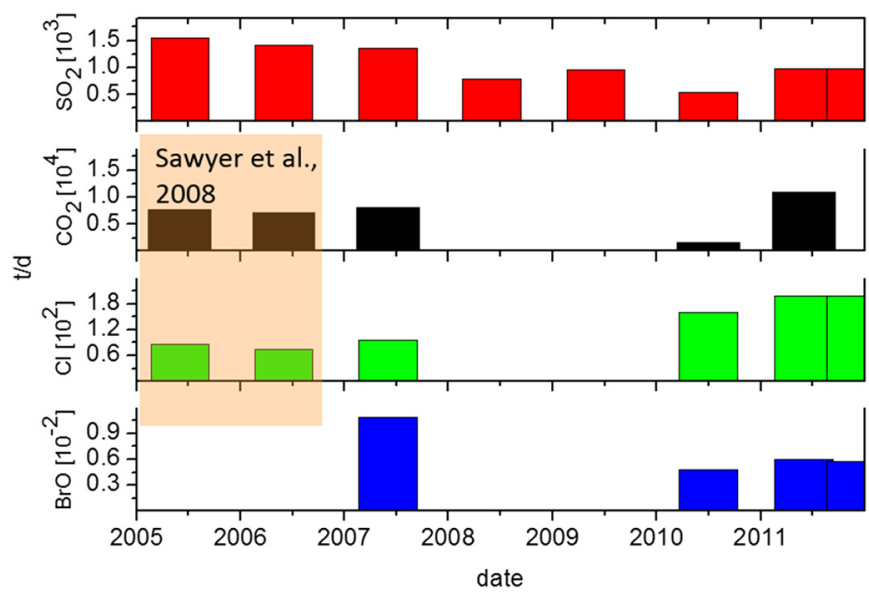

Fig. 5. Mean fluxes for each campaign are presented. The shown $\mathrm{SO}_{2}$ flux is the annual mean. The fluxes of all other gases are calculated from the annual mean $\mathrm{SO}_{2}$ flux and the respective mean gas $/ \mathrm{SO}_{2}$ ratio during a single campaign. 


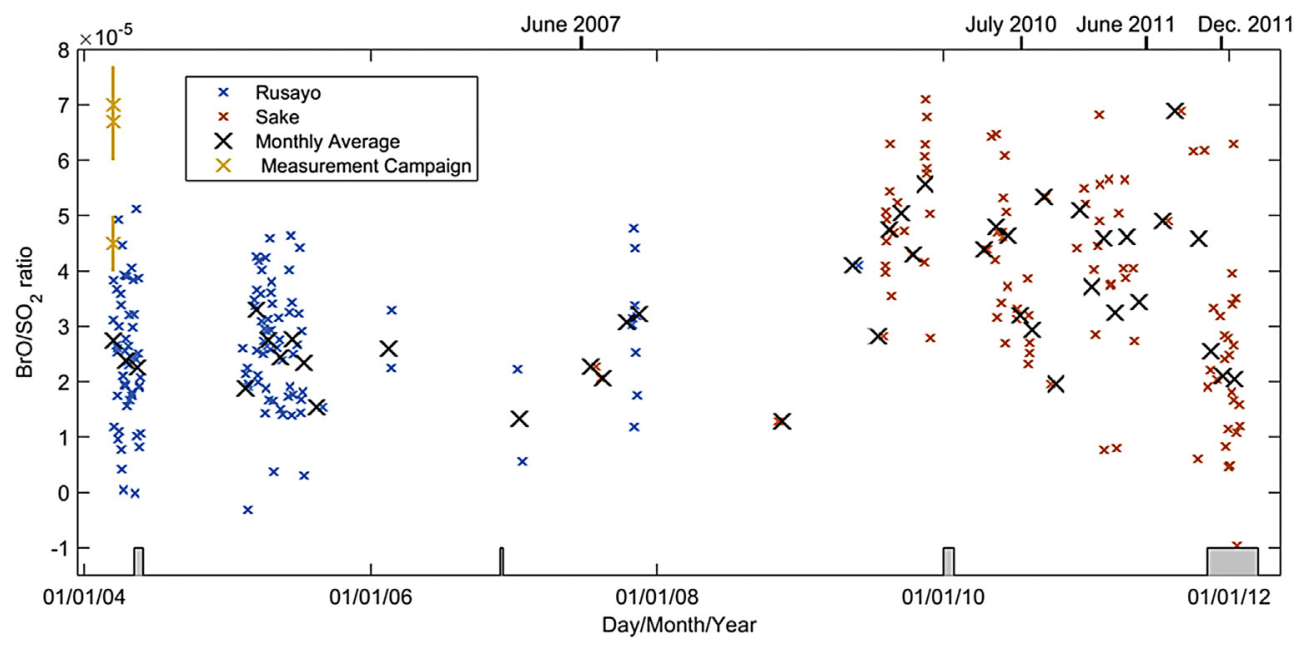

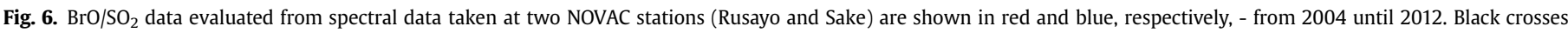

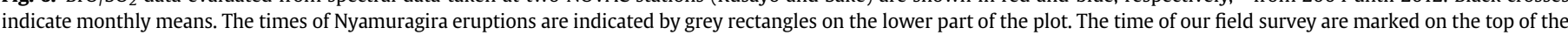
plot. (For interpretation of the references to colour in this figure legend, the reader is referred to the web version of this article.)

surface. Afterwards when permeability is decreasing $\mathrm{CO}_{2}$ (and bromine) already exsolved cannot be any more properly degassed (2nd June 2011) and pressure starts to build up, until accumulated gas at a deeper level 'pushes up' and eventually resume the convection but maybe also partly escaping into fractures which might be formed at the inner walls of the conduit. By bringing fresh un-

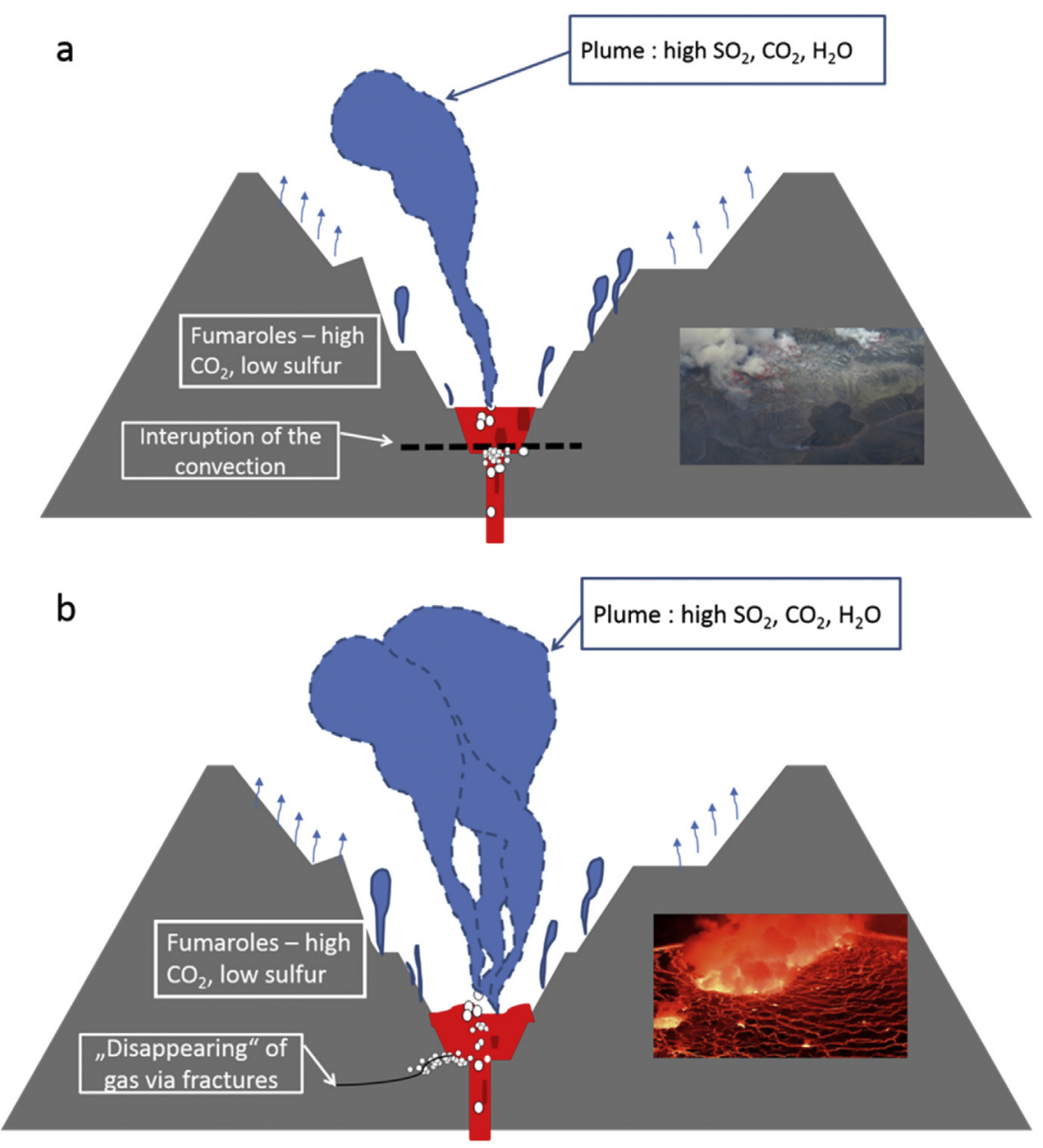

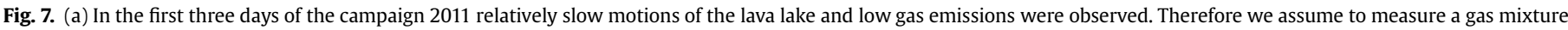

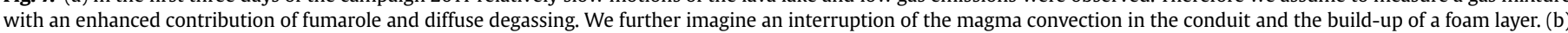

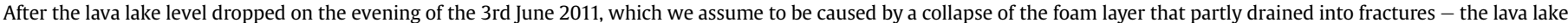

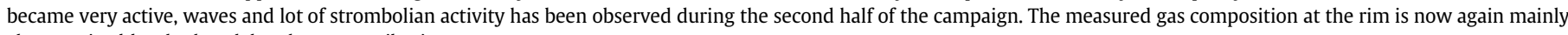
characterized by the lava lake plume contribution. 
degassed magma up, in particular un-degassed in sulfur, the $\mathrm{CO}_{2} /$ $\mathrm{SO}_{2}$ and $\mathrm{BrO} / \mathrm{SO}_{2}$ ratios decrease and return to former (2007 and 2010) observed values. The convection might be even a bit enhanced in the beginning after the interruption before the systems finds back to a meta-stable equilibrium. This would be mirrored by our observation of a very "lively" lava lake during the following days (4th, 5th and 6th June 2011).

Such an interruption of the convection inside the conduit might occur frequently but would cause only relatively short term variations usually. That the large scale convection on longer time scales seems to be far more stable is shown by the relatively stable degassing pattern shown in Arellano et al. (2016, this issue). The mean $\mathrm{SO}_{2}$ emission rate since the NOVAC network was installed seems to be still similar to that reported by (Le Guern, 1987) during the expedition of 1959, when the level of the lava lake was also similar.

Comparing our observations of the various years we observe a general increase in the $\mathrm{Cl} / \mathrm{S}$ ratio, caused only partly by a decreasing $\mathrm{SO}_{2}$ emissions, as we still measure an increase in chlorine emissions if we scale our $\mathrm{Cl} / \mathrm{S}$ ratio with the $\mathrm{SO}_{2}$ fluxes and assuming that all $\mathrm{S}$ (or at least the major part) is released in form of $\mathrm{SO}_{2}$. The as well increasing $\mathrm{CO}_{2}$ emission in 2011 could be also caused detecting a stronger contribution of fumarolic and diffuse ground degassing from the crater rim of Nyiragongo in the more recent data. Scaling the $\mathrm{CO}_{2} / \mathrm{SO}_{2}$ ratios (which might contain fumarolic + diffuse contributions) with the plume $\mathrm{SO}_{2}$ flux could lead then to an error prone $\mathrm{CO}_{2}$ flux.

Such a complex system does not allow to draw straightforward conclusions from our observations. Enhanced chlorine emissions and a decrease in $\mathrm{SO}_{2}$ fluxes could be generally interpreted as a more degassed magma reservoir, which fits still with an apparently increased $\mathrm{CO}_{2} / \mathrm{SO}_{2}$ ratios, assuming that an increased portion of the measured gas originates from ground and/or fumarole degassing. A degassed magma reservoir would be difficult to explain with an increased or stable $\mathrm{CO}_{2}$ emissions as shown in Fig. 4 and Table 1. However, those results might be caused by a simple miscalculation. An error could be caused by assuming no fumarole and ground degassing and therefore overestimating the $\mathrm{CO}_{2} / \mathrm{SO}_{2}$ ratio and scaling it with the $\mathrm{SO}_{2}$ flux. Although it might be difficult to imagine an exhausting source, this cannot be excluded. Separation of the various degassing sources and determination of their strengths should be conducted in the future. Another possible interpretation might be again $\mathrm{CO}_{2}$ degassing from a deeper source which does not enter into the upper part of the conduit. Assuming again a sufficient permeable system which allows the $\mathrm{CO}_{2}$ (and bromine) to pass could therefore cause higher $\mathrm{CO}_{2} / \mathrm{SO}_{2}$ and $\mathrm{BrO} / \mathrm{SO}_{2}$ ratios parallel to increasing $\mathrm{Cl} / \mathrm{S}$ ratios. This might work for a certain time, as long as permeability is conserved and the variability of the alteration of the source small.

\section{Conclusions}

In this work, the plume of Nyiragongo has been studied for short time series of several days up to a week between 2007 and 2011. The results show similar variations of the "BrO"-fluxes and $\mathrm{CO}_{2}$-fluxes regarding the average values of the different years. Also similar short-term variations of both ratios $\left(\mathrm{BrO} / \mathrm{SO}_{2}\right.$ and $\left.\mathrm{CO}_{2} / \mathrm{SO}_{2}\right)$ could be observed in June 2011.

Sawyer et al. (2008) described the gas emission as very stable during their visits for the years 2005-2007. In contrast we observed significant changes between data collected since our first visit in 2007 in comparison to those obtained in 2010 and 2011. Both observations fit to the more continuous obtained data taken from the NOVAC network regarding $\mathrm{SO}_{2}$ fluxes (Arellano et al., this issue) and the $\mathrm{BrO} / \mathrm{SO}_{2}$ ratios presented here.
During our field surveys higher $\mathrm{CO}_{2} / \mathrm{SO}_{2}$ ratios are accompanied by higher lava lake levels. The reported lava lake levels in 1959 and 1972 have been higher than during our period of investigation and showed a higher $\mathrm{CO}_{2} / \mathrm{SO}_{2}$ ratios than the once measured in this study. Therefore supporting our short term observation of this behavior also on a longer time frame.

Our observations indicate that changes of the gas composition of Nyiragongo might accompany variations/oscillations of the lava lake level occurring in short and long-term time scales. Future studies on the frequency of the lake level changes should focus on the understanding if these variations take place periodically and if gas composition changes are always related to changes of the lava lake level. This information will give insights into the magma plumbing system of Nyiragongo volcano and might shed light in a more global context on the meaning of $\mathrm{BrO} / \mathrm{SO}_{2}$ changes in a volcanic system. It will be interesting to see the further evolution of the $\mathrm{CO}_{2} / \mathrm{SO}_{2}$ and $\mathrm{Cl} / \mathrm{S}$ ratios during the next years, possibly seeing which of our interpretations above are closer to reality, although we want to state that the described interpretations do not necessarily exclude each other and could be also combined.

\section{Acknowledgements:}

The authors thanks all people working at OVG and UNOPS for financial support during several campaigns. N. Bobrowski thanks further the DFG for funding for data evaluation and support during writing (BO 3611/1-2). The authors thank for the possibility of alkaline trap samples analysis at INGV Palermo and the support from SIDA (Swedish International Development Cooperation Agency) for operation of the NOVAC stations by OVG. We further like to thank Thor Hansteen for his advices, question and comments, which helped to improve the manuscript significantly.

\section{References}

Arellano, S., Yalire M., Galle B., Bobrowski, N., Johansson M., Norman P., Dingwell A. (in this issue) Magnitude, intensity and impact of SO2 gas emissions from Nyiragongo volcano during 2004-2012002E.

Aiuppa, A., Federico, C., Franco, A., Giudice, G., Guirriere, S., Inguaggiato, S. Liuzzo, M., McGonigle, A.J.S., Valenza, M., 2005. Emission of trace halogens from a basaltic volcano: Mt. Etna. Geochem. Geophys. Geosys. 6 http://dx.doi.org/ 10.1029/2005GC000965.

Aiuppa, A., Federico, C., Giudice, G., Gurrieri, S., Liuzzo, M., Shinohara, H., Favara, R. Valenza, M., 2006. Rates of carbon dioxide plume degassing from Mount Etna volcano. J. Geophys. Res. Solid Earth 111, B09207. http://dx.doi.org/10.1029/ 2006 JB004307.

Bobrowski, N., Giuffrida, G., 2012. Bromine monoxide/sulphur dioxid ratios in relation to volcanological observations Mt Etna 2006-2009. Solid Earth 4, 475-505.

Bobrowski, N., von Glasow, R, Aiuppa, A., Inguaggiato, S., Louban, I., Ibrahim, O.W. Platt, U., 2007. Reactive halogen chemistry in volcanic plumes. J. Geophys. Res. 112 http://dx.doi.org/10.1029/2006JD007 206. D06 311.

Bobrowski, N., Kern, C., Hörmann, C., Wagner, T., Platt, U., 2010. $\mathrm{SO}_{2}$ evaluation in the wavelength range 360-390 nm. AMT. http://dx.doi.org/10.5194/amt-3-12010.

Bobrowski, N., von Glasow, R., Giuffrida, G.B., Tedesco, D., Aiuppa, A., Yalire, M., Arellano, S., Johansson, M., Galle, B., 2015. Gas emission strength and evolution of the molar ratio of $\mathrm{BrO} / \mathrm{SO}_{2}$ in the plume of Mt. Nyiragongo in comparison to Mt. Etna. J. Geophys. Res. Atmos. 120 (1), 277-291.

Burgi, P.-Y., Darrah, T.H., Tedesco, D., Eymold, W.K., 2014. Dynamics of the mount Nyiragongo lava lake. J. Geohys. Res. Solid Earth 119, 4106-4122.

Bussemer, M., 1996. Der Ring-Effekt: Ursachen und Einfluss auf die spektroskopische Messung stratosphärischer Spurenstoffe (Diploma thesis). Institut für Umweltphysik, Universität Heidelberg.

Calabrese, S., Scaglione, S., Milazzo, S., D'Alessandro, W., Bobrowski, N., Giuffrida, G.B., Tedesco, D., Parello, F., Yalire, M., 2014. Passive degassing at Nyiragongo (D.R. Congo) and Etna (Italy) volcanoes. Ann. Geophys. Special Issue Atmos. Emiss. Volcanoes. http://dx.doi.org/10.4401/ag-6753.

Chaigneau, M., et al., 1960. Composition des gaz volcaniques du lac de lave permanent du Nyiragongo (Congo Belge), C. R. Hebd. Seances Acad. Sci. 250, $2482-2485$

Chakrabarti, R., Basu, A.R., Santo, A.P., Tedesco, D., Vaselli, O., 2009. Isotopic and geochemical evidence for a heterogeneous mantle plume origin of the Virunga volcanics, Western rift, East African Rift system. Chem. Geol. 259, 273-289. 
Cuoco, E., Spagnuolo, A., Balagizi, C., De Francesco, S., Tassi, F., Vaselli, O., Tedesco, D., 2013. Impact of volcanic emissions on rainwater chemistry: the case of Mt. Nyiragongo in the Virunga volcanic region (DRC). J. Geochem. Explor. 125, 69-79.

Fayt, C., van Roozendael, M., 2001. WinDOAS 2.1-Software User Manual, Belgisch Instituut voor Ruimte-Aeronomie Institut d'Ae'ronomie Spatiale de Belgique. Belgium, Brussels.

Galle, B., Johannson, M., Rivera, C., Zhang, Y., Kihlmann, M., Kern, C., Lehmann, T., Platt, U., Arellano, S., Hidalgo, S., 2010. Network for Observation of Volcanic and Atmospheric Change (NOVAC) - A global network for volcanic gas monitoring: network layout and instrument description. J. Geophys. Res. 115, D05304. http://dx.doi.org/10.1029/2009JD011823.

Gerlach, T.M., 1980. Chemical characteristics of the volcanic gases from Nyiragongo lava lake and the generation of $\mathrm{CH} 4$-rich fluid inclusions in alkaline rocks. J. Volc. Geotherm. Res. 8, 177-189.

Götzen, Von, 1897. À travers l'Afrique : de l'est à l'ouest. unpublished original reports (available is the French National Library).

Kraus, S., 2001. DOASIS, DOAS Windows Software, Presentation at the 1st international DOAS Workshop, 13-14. September 2001, Heidelberg, Germany.

Le Guern, F., 1987. Mechanism of energy transfer in the lava lake of Niragongo (Zaire), 1959 - 1977. J. Volcanol. Geotherm. Res. 31, 17-31.

Lübcke, P., Bobrowski, N., Arellano, S., Galle, Bo, Garzón, G., Vogel, Leif, Platt, U., 2014. $\mathrm{BrO} / \mathrm{SO}_{2}$ molar ratios from scanning DOAS measurements in the NOVAC network. Solid Earth Discuss. 5, 409-429.

Platt, U., Bobrowski, N., 2015. Quantification of Volcanic Reactive Halogen Emissions, Chapter 8 in "Volcanism and Global Change". Cambridge University Press, pp. 115-132.

Platt, U., Stutz, J., 2008. Differential Optical Absorption Spectroscopy - Principles and Applications, Physics of Earth and Space Environments, First Edition. Springer, Berlin, Heidelberg, 25 New York, p. 597.
Platz, T., Foley, S.F., André, L., 2004. Low-pressure fractionation of the Nyiragongo volcanic rocks, Virunga province, D.R. Congo. J. Volcanol. Geotherm. Res. 136 (Issues 3-4), 269-295.

Pottier, Y., 1978. Première éruption historique du Nyiragongo et manifestations adventives simultanées du Volcan Nyamulagira (Chaine des Virunga - Kivu Zaïre: dec. 76-Juin 77). Mus Roy Afr Centr, Tervuren (Belg). Dept. Geol. Mineral. $157-175$.

Sawyer, G.M., Carn, S.A., Tsanev, V.I., Oppenheimer, C., Burton, M., 2008. Investigation into magma degassing at Nyiragongo volcano. Democr. Repub. Congo 9 (N. 2).

Shinohara, H., 2005. A new technique to estimate volcanic gas composition: plume measurements with a portable multi-sensor system,. J. Volcanol. Geotherm. Res. 143, 319-333. http://dx.doi.org/10.1016/j.jvolgeores. 2004.12.004.

Smets, B., d'Oreye, N., Geirsson, H., Kervyn, M., Kervyn, F., 2016. Insights into the Dynamics of the Nyiragongo Lava Lake Level, EGU2016-8350 (Vienna, Austria).

Tazieff, H., 1975. Nyiragongo ou le volcan interdit, p. 288 (Flammarion, France).

Tazieff, H., 1977. An exceptional eruption: Mt Nyiragongo, Jan 10th 1977. Bull. Volcanol. 40 (3), 189-200.

Tedesco, D., Tassi, F., Vaselli, O., Poreda, R.J., Darrah, T., Cuoco, E., Yalire, M.M., 2010 Gas isotopic signatures (He, C, and $\mathrm{Ar}$ ) in the Lake Kivu region (western branch of the East African rift system): geodynamic and volcanological implications. J. Geophys. Res. 115, B01205.

Witham, F., Llewellin, E.W., 2006. Stability of lava lakes. J. Volcanol. Geotherm. Res. 158 (3), 321-332.

Witham, F., Woods, A.W., Gladstone, C., 2006. An analogue experimental model of depth fluctuations in lava lakes. Bull. Volcanol. 69, 51-56.

Wittmer, J., Bobrowski, N., Liotta, M., Giuffrida, G., Calabrese, S., Platt, U., 2014 Active alkaline traps to determine acidic-gas ratios in volcanic plumes. Sampl. Tech. Anal. Methods, G3 15, 2797-2820. http://dx.doi.org/10.1002/ 2013 GC005133. 